\title{
Strengthened Relationship between Tropical West Pacific and Midsummer Precipitation over Northeast China after the Mid-1990s 0
}

\author{
TINGTING HAN \\ Collaborative Innovation Center on Forecast and Evaluation of Meteorological Disasters/Key Laboratory of Meteorological \\ Disaster, Ministry of Education, Nanjing University of Information Science and Technology, Nanjing, and Nansen-Zhu \\ International Research Centre, Institute of Atmospheric Physics, Chinese Academy of Sciences, Beijing, China \\ MiNGHUA ZHANG \\ School of Marine and Atmospheric Sciences, Stony Brook University, State University of New York, Stony Brook, New York, \\ New York, and International Center for Climate and Environmental Sciences/IAP, Chinese Academy of Sciences, \\ Beijing, China \\ BotaO ZHOU AND XIN HaO \\ Collaborative Innovation Center on Forecast and Evaluation of Meteorological Disasters/Key Laboratory of Meteorological \\ Disaster, Ministry of Education, Nanjing University of Information Science and Technology, Nanjing, and Nansen-Zhu \\ International Research Centre, Institute of Atmospheric Physics, Chinese Academy of Sciences, Beijing, China

\section{SHANGFENG LI} \\ Jilin Provincial Key Laboratory of Changbai Mountain Meteorology and Climate Change, Laboratory of Research for \\ Middle-High Latitude Circulation Systems and East Asian Monsoon, Institute of Meteorological Sciences of Jilin Province, \\ Changchun, China
}

(Manuscript received 24 December 2019, in final form 6 May 2020)

\begin{abstract}
The relationship between the tropical west Pacific (TWP) and East Asian summer monsoon/precipitation has been documented in previous studies. However, the stability for the signals of midsummer precipitation in the TWP sea surface temperature (SST_TWP), which is important for climate variation, has drawn little attention. This study identifies a strengthened relationship between the leading empirical orthogonal function mode (EOF1) of midsummer precipitation over Northeast China (NEC) and the SST_TWP after the mid1990s. The EOF1 mode shows a significant positive correlation with the SST_TWP for 1996-2016, whereas the relationship is statistically insignificant for 1961-90. Further results indicate that the North Pacific multidecadal oscillation (NPMO) shifts to a positive phase after the 1990s. In the positive NPMO phase, the anomalous circulation over the northeast Pacific expands westward over the central North Pacific-Aleutian Islands region. Concurrently, the SST_TWP-associated wavelike pattern propagates northeastward from the west Pacific to the northwest Pacific and farther to the North Pacific, facilitating the poleward expansion and intensification of the SST_TWP-related circulation anomalies over the North Pacific. Therefore, the SST_ TWP has an enhanced influence on NEC precipitation through the modulation of the circulation anomalies over the central North Pacific-Aleutian Islands region after the mid-1990s. Additionally, the tropical anticyclone/cyclone associated with the SST_TWP expands westward to South China, exerting an intensified impact on meridional wind anomalies along eastern China and on moisture transport over NEC. These conditions jointly contribute to the strengthened relationship between the SST_TWP and the EOF1 mode of NEC midsummer precipitation after the mid-1990s.
\end{abstract}

Supplemental information related to this paper is available at the Journals Online website: https://doi.org/10.1175/JCLI-D-190957.s1.

Corresponding author: Dr. Tingting Han, hantt08@126.com

DOI: 10.1175/JCLI-D-19-0957.1

(C) 2020 American Meteorological Society. For information regarding reuse of this content and general copyright information, consult the AMS Copyright Policy (www.ametsoc.org/PUBSReuseLicenses). 


\section{Introduction}

Northeast China (NEC), located at the middle to high latitudes, is one of China's vital grain production bases. The large climate variability in this region, especially in terms of precipitation variation and distribution, exerts a substantial impact on crop growth, yield production, social development, and ecological construction. Therefore, it is essential to explore the contributors that are associated with precipitation variation in this region.

Previous studies concerning summer precipitation in NEC have documented the influence of various atmospheric regimes, such as the East Asian monsoon systems (Sun et al. 2007, 2017; Cao et al. 2018), blocking high at high latitudes (Yao and Dong 2000), cold vortex activities in NEC (Shen et al. 2011), soil moisture content in northwest Eurasia (Zhu 2011), and the North Atlantic Oscillation (Sun and Wang 2012). For example, the wintertime Northern Hemisphere annual mode and North Pacific Oscillation both affect NEC precipitation during the following summer through modulation of the cold vortex (Liu et al. 2002; He et al. 2006). Z. Gao et al. (2014) identified that the late spring precipitation anomaly in the Huang-Huai region is significantly connected with NEC summer precipitation via local soil moisture anomalies. Additionally, Han et al. (2015) revealed a significant decrease in NEC precipitation after the late 1990s, and they attributed this decadal shift to the combined effects of the weakened Northeast Asian summer monsoon and changes in the Arctic sea ice area. Wang and He (2015) stated that the Pacific SST anomalies, the Arctic sea ice anomalies, and warming over both the European continent and the Caspian Sea contributed cooperatively to the severe drought in North China and Northeast Asia during summer 2014. Recently, Han et al. (2019b) reported that the preceding soil moisture content in central Asia and the tropical Atlantic SST are efficient indicators of summer precipitation amount and extreme precipitation events in NEC.

Considerable effort has been devoted for the investigation of the connection between SST anomalies in the key areas and climatic variability over NEC (Bai 2001; Hu et al. 2003; Sun and Wang 2006; Zhou et al. 2013). Feng et al. (2006) suggested that SST in the southwest Indian Ocean and in the North Atlantic Ocean has different effects on midsummer precipitation over NEC. The springtime SST contrast between the tropical Indian Ocean and the western Pacific is significantly correlated with summer precipitation at NEC (Cao et al. 2013). Feng and Chen (2016) noted that warming SST anomalies in the North Pacific during autumn are followed by strong southeasterly and meridional moisture transport over NEC, leading to regionally intensified snow events. Additionally, Han et al. (2018a) determined that winter precipitation at NEC had an intimate association with SST anomalies in the tropical Indian Ocean before the 1990s and with the North Atlantic SST anomalies subsequently.

Specifically, the tropical west Pacific (TWP), which represents the largest warm pool on Earth, is one of the water vapor sources for summer precipitation over China (Li et al. 2014; Sun and Wang 2014a, 2015; Zhou 2014; Li et al. 2016). Using uncoupled atmospheric and coupled oceanic-atmospheric experiments, Yoo et al. (2004) demonstrated the contribution of the TWP SST anomalies to the climate variability in East and Southeast Asia. Huangfu et al. (2015) stated that the earlier outbreak of the South China Sea summer monsoon after the late 1990s is attributed to the recent warming of the warm pool. Furthermore, the SST in the tropical west Pacific exhibits a striking warming trend after the 1990s (H. Gao et al. 2014). It may have an influence on the signals of midsummer precipitation in the TWP SST. Therefore, this study focuses on the relationship between the SST anomaly in the TWP and summer precipitation at NEC.

In recent decades, interdecadal changes in the relationship between SST signals and the East Asian atmospheric circulation have received increasing attention (e.g., Chang et al. 2000; Gao et al. 2017; Deng et al. 2019; Ma et al. 2019). Wang (2000) was the first to report the instability in the relationship between El Niño-Southern Oscillation (ENSO) and the East Asian climate. Moreover, Wu et al. (2011) reported that the relationship of summer temperature at NEC and a tripole SST anomaly pattern in the North Atlantic is closer after the 1980s than before, and they attributed this strengthening to the persistence of the tripole SST pattern. Analyses of observations and numerical simulations have indicated that the eastern Pacific ENSO during spring has had intensified influence on NEC precipitation in the following summer since the late 1990s (Han et al. 2017). In addition, the spring SST anomaly in the tropical Indian Ocean has been revealed as a potential indicator of subsequent midsummer precipitation over NEC since the late 1980s (Han et al. 2018b). Wu et al. (2014) found that the SST anomalies in the tropical Indo-western Pacific play a major role in summer temperature in NEC after the 1990s. Accordingly, there is a need for in-depth scientific analysis to elucidate potential instability in the relationship between the TWP SST and summer precipitation over NEC.

In addition, Shen et al. (2011) have shown that the regimes that affect NEC precipitation are significantly different between early summer and midsummer. 

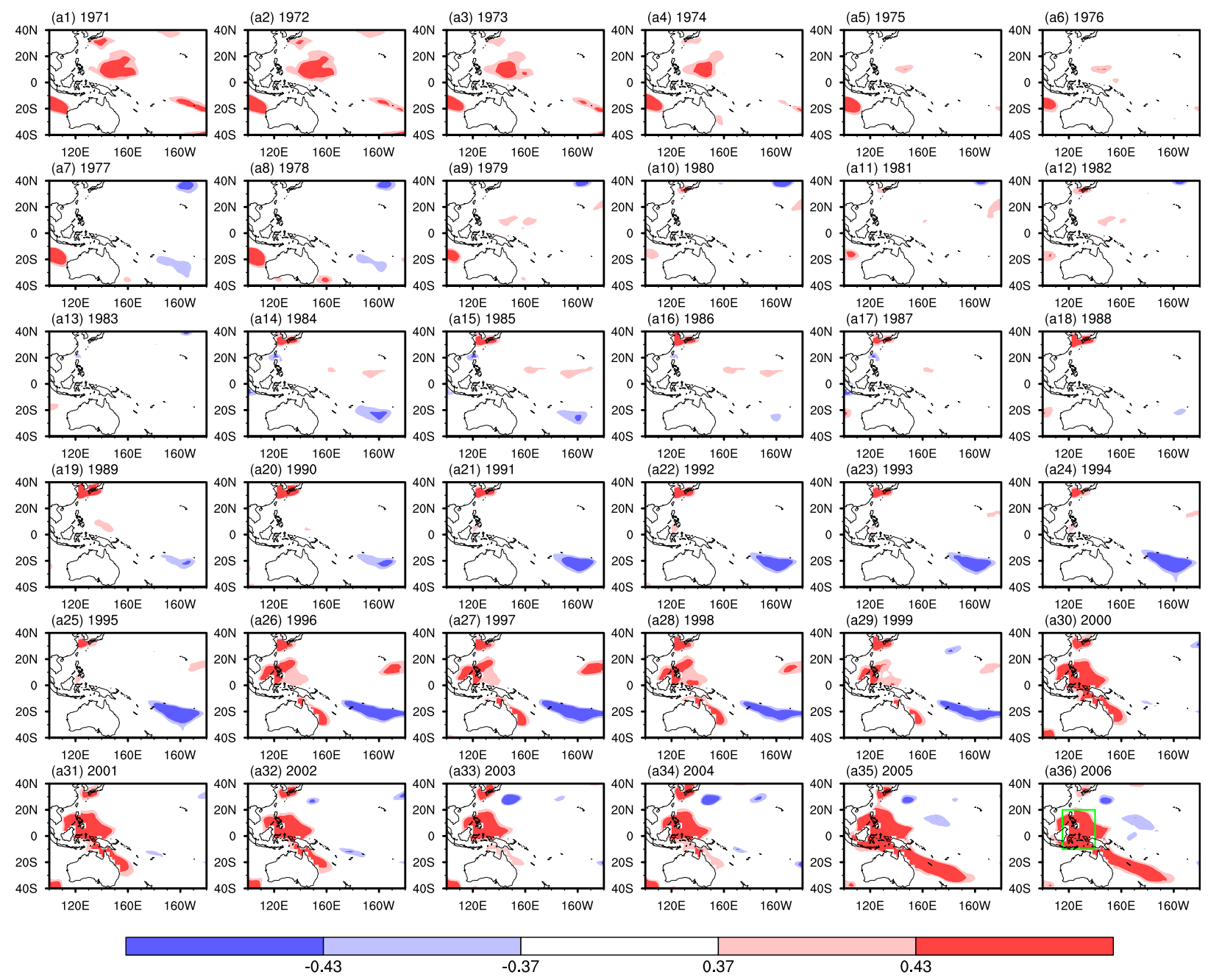

FIG. 1. Sliding correlation coefficients between midsummer sea surface temperature (SST) in the tropical west Pacific and the PC1 associated with the EOF1 mode of simultaneous precipitation over Northeast China (NEC). The sliding window is 21 years with 1-yr intervals. The year of each panel indicates the central year of the window. Dark (light) shadings indicate the values that significantly exceed the 95\% (90\%) confidence level, estimated using Student's $t$ test. (a36) The green rectangular area represents the selected region for the SST_TWP index.

Midsummer is a period of high concentration of precipitation at NEC. Thus, this study focuses on midsummer precipitation in NEC. Interestingly, Han et al. (2019a) revealed that the leading EOF (EOF1) mode of midsummer precipitation over NEC displays homogenous anomalies. The time series corresponding to the EOF1 mode (hereafter, PC1) are found highly covariant with midsummer precipitation over NEC during 1961-2016 (correlation coefficient: 0.97 ), implying that the leading EOF mode represents well the variability of NEC midsummer precipitation. Therefore, the purpose of this study is to explore the changes in the relationship between the TWP SST and the EOF1 mode of midsummer precipitation over NEC.
The remainder of this paper is organized as follows. Section 2 describes the datasets and methods used in this study. Details of both the strengthened relationship between the TWP SST and the EOF1 mode of NEC precipitation and the possible underlying mechanisms are given in sections 3 and 4, respectively. Finally, a brief conclusion and discussion are presented in section 5 .

\section{Data and methods}

An advanced daily precipitation dataset (i.e., CN05.1) is used in the present study for 1961-2016 (Wu and Gao 2013). This dataset, which has reasonably high resolution $\left(0.25^{\circ} \times 0.25^{\circ}\right)$, is constructed by interpolating data 
from over 2400 meteorological stations in China. This dataset has been widely used in the regional climate changes and the high-resolution climate model validation at China (Zhou et al. 2016; Wang et al. 2017). Another monthly precipitation dataset from the Global Precipitation Climatology Centre (GPCC) is also used to confirm the results (Becker et al. 2012). In this study, NEC is defined as the region of China north of $38^{\circ} \mathrm{N}$ and east of $115^{\circ} \mathrm{E}$. Midsummer precipitation is calculated as the summation of daily precipitation amounts from 1 July to 31 August annually. The EOF1 mode and the corresponding time series (i.e., PC1) are obtained by performing EOF analysis on of NEC midsummer precipitation.

The monthly atmospheric reanalysis dataset for 19482016 (resolution: $2.5^{\circ} \times 2.5^{\circ}$ ) used in this study is obtained from the National Center for Environment Prediction and National Center for Atmospheric Research (NCEPNCAR; Kalnay et al. 1996). Monthly SST data on a $2.0^{\circ} \times$ $2.0^{\circ}$ grid are extracted from the National Oceanic and Atmosphere Administration (NOAA) Extended Reconstructed SST version 5 dataset for 1854-2016 (Huang et al. 2017). Here, midsummer refers to the average for July and August.

The common time period for this study is 1961-2016. Regression, correlation, and composite analyses are employed to investigate the atmospheric circulation anomalies associated with the NEC precipitation and SST in the tropical west Pacific. The Student's $t$ test is used to determine statistical significance. Additionally, linear trends have been removed prior to analysis from the precipitation and all the fields, to isolate interannual variations.

\section{Strengthened relationship between the TWP SST and the EOF1 mode of midsummer precipitation at NEC}

Figure 1 presents sliding correlation coefficients between the PC1 and the simultaneous SST in the west Pacific with a 21-yr moving window. As an example, 1971 is the central year for the period 1961-81. It can be seen that positive correlation coefficients are evident in the TWP after the mid-1990s and expand southeastward over time, which implies a strengthened relationship between the TWP SST and the leading mode of NEC precipitation after the mid-1990s. Similar results can be obtained based on the SST dataset from the Met Office Hadley Centre (Fig. S1 in the online supplemental material).

To facilitate analysis, an SST_TWP index is defined as the area-weighted averaged SST within the TWP $\left(10^{\circ} \mathrm{S}-\right.$ $\left.20^{\circ} \mathrm{N}, 115^{\circ}-140^{\circ} \mathrm{E}\right)$. The 21 -yr sliding correlation coefficients

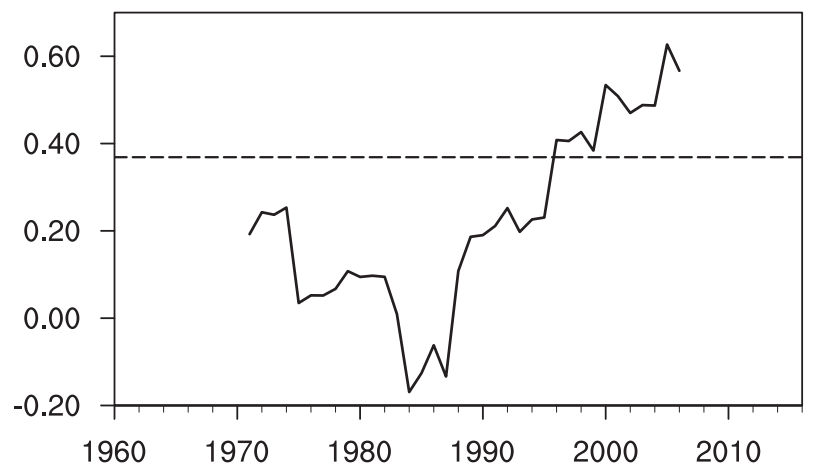

FIG. 2. The 21-yr sliding correlation coefficients between the PC1 and SST_TWP indices. The horizontal line denotes the $90 \%$ confidence level, estimated using the Student's $t$ test.

between the PC1 and SST_TWP indices are insignificant before the 1990s, whereas the positive correlation strengthens and becomes statistically significant after the mid-1990s (Fig. 2). When the sliding window width changes to 19 and 23 years, such intensified connection is apparent (Fig. S2). To verify the decadal shift in the interannual relationship between the SST_TWP and NEC summer precipitation after the mid-1990s, and to avoid the effects related to the choice of sliding window width, we took two subperiods: 1961-90 (hereafter P1) and 1996-2016 (hereafter P2), by removing the middle transitional 5 years. The correlation coefficient between the SST_TWP and PC1 indices is 0.07 during P1 (insignificant) and 0.57 during P2 (above the $99 \%$ confidence level). The respective spatial distributions of precipitation anomalies over NEC associated with the SST_TWP index during the two subperiods are depicted in Fig. 3, based on the CN05.1 grid data and the GPCC data. Consistent changes are observed between these two datasets. During P1, the precipitation anomalies are barely significant except for a tiny area in northern parts. By contrast, during P2, warming SST anomalies are accompanied by pronounced positive precipitation anomalies over NEC, along with large values in southern NEC, which is consistent with the leading EOF mode of NEC midsummer precipitation (Han et al. 2019a). These results confirm that the TWP SST has been in a significant connection with NEC midsummer precipitation since the mid-1990s.

To further illustrate the strengthening of the SST TWP-precipitation relationship after the mid-1990s, the associated atmospheric circulation anomalies are examined. The features of SLP anomalies with respect to the PC1 index before and after the 1990s are shown in Figs. 4a and 4b, respectively. For the two subperiods, positive precipitation anomaly co-occurs with profound 

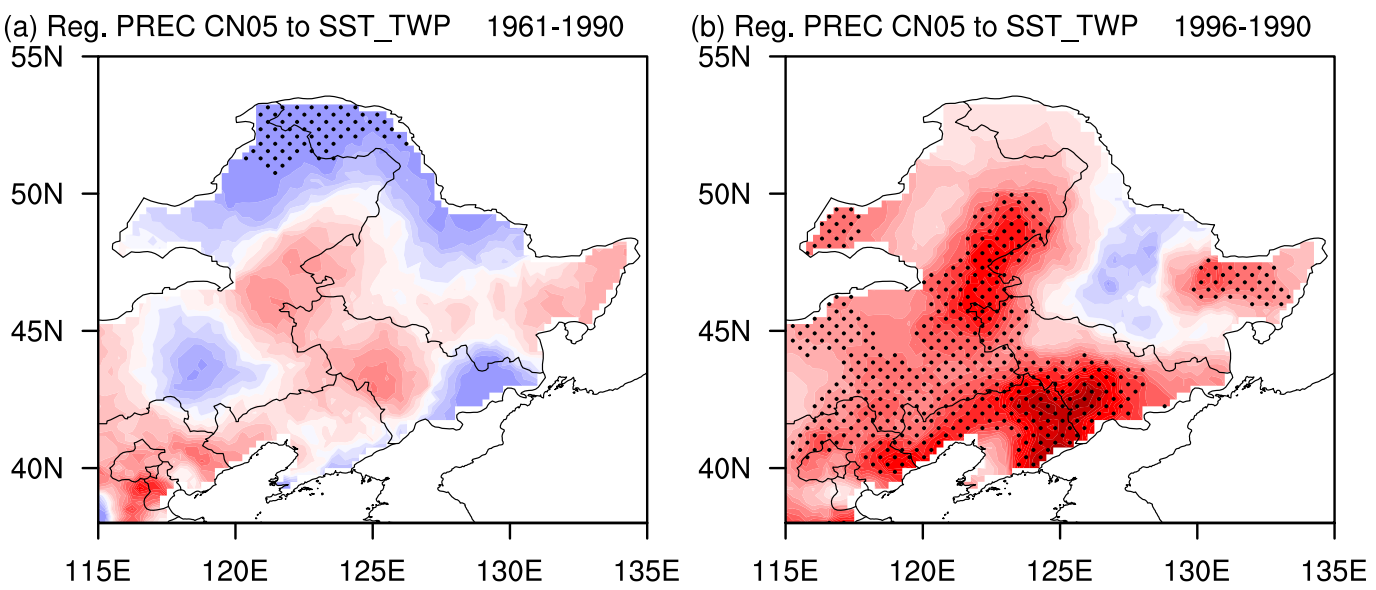

(c) Reg. PREC GPCC to SST_TWP 1961-1990

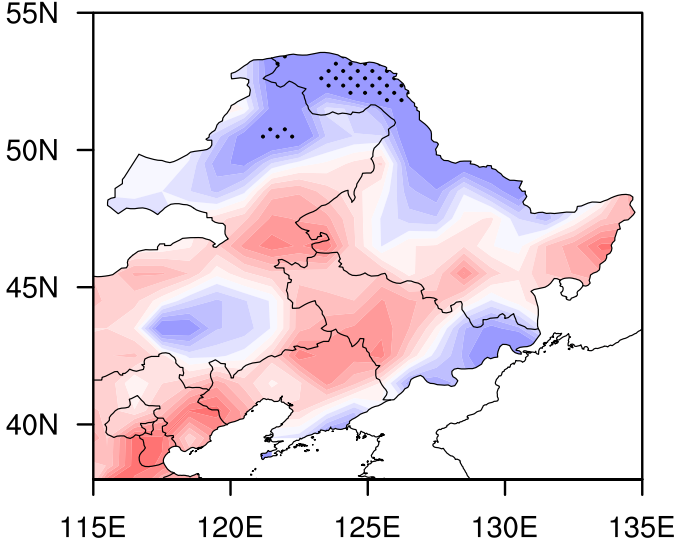

(d) Reg. PREC GPCC to SST_TWP 1996-1990

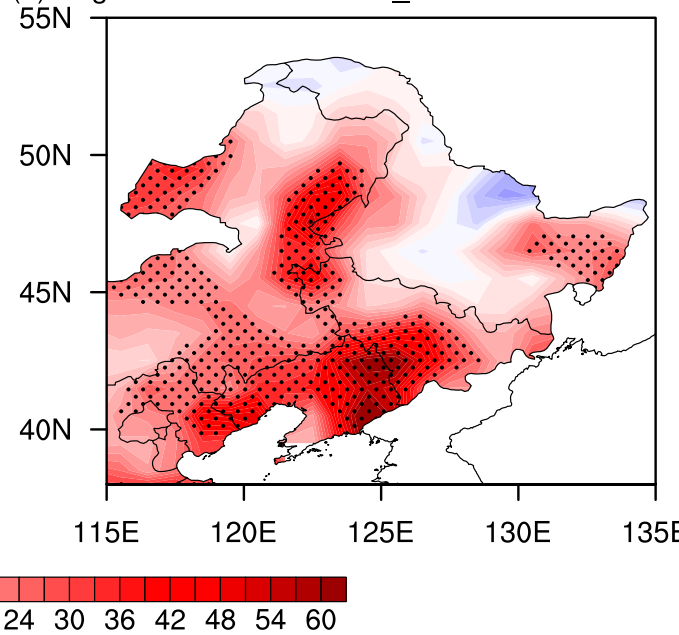

FIG. 3. Linear regression pattern of midsummer precipitation based on (a),(b) the CN05.1 dataset and (c),(d) the GPCC dataset (mm) against the SST_TWP index for (left) 1961-90 and (right) 1996-2016. Stippled areas indicate the values that significantly exceed the $90 \%$ confidence level, estimated using the Student's $t$ test.

positive SLP anomalies over the Aleutian Islands and the central North Pacific, and negative anomalies over northern China. Interestingly, significant positive SLP anomalies appear over the subtropical west Pacific and the tropical central Pacific during $\mathrm{P} 2$, which are not present during P1. It suggests an intensified linkage between the tropical circulation anomalies and NEC precipitation after the mid-1990s. Additionally, warming SST anomalies in the TWP are concurrent with prominent positive SLP anomalies over the tropical Pacific and negative values over the Maritime Continent during $\mathrm{P} 1$, along with insignificant anomalies over East Asia excluding parts of NEC (Fig. 4c). However, the positive SLP anomalies expand poleward to the Aleutian Islands and westward to southern China during P2 (Fig. 4d), which are in agreement with the circulation anomalies related with the NEC midsummer precipitation (Fig. 4b).
As shown in Figs. 4a and 4b, the anomalous circulation over the central North Pacific-Aleutian Islands region is influential to NEC precipitation during both subperiods. Thus, an Aleutian circulation index (hereafter, Aleutian index for simplicity) is defined as the area-weighted average of SLP within the central North Pacific-Aleutian Islands region $\left(30^{\circ}-60^{\circ} \mathrm{N}, 160^{\circ} \mathrm{E}-\right.$ $150^{\circ} \mathrm{W}$; the rectangular area in Fig. 4). Consistently, the Aleutian index exhibits significant correlation with the PC1 before and after the 1990s, with correlation coefficients of 0.41 and 0.42 , respectively. As illustrated in Table 1, the correlation between the SST_TWP and Aleutian indices is insignificant before the 1990s $(R=$ 0.13 ), as expected; however, their relationship becomes statistically significant thereafter $(R=0.69$; above the $99 \%$ confidence level). Therefore, the strengthened relationship between the SST_TWP and the circulation over the central North Pacific-Aleutian Islands region 

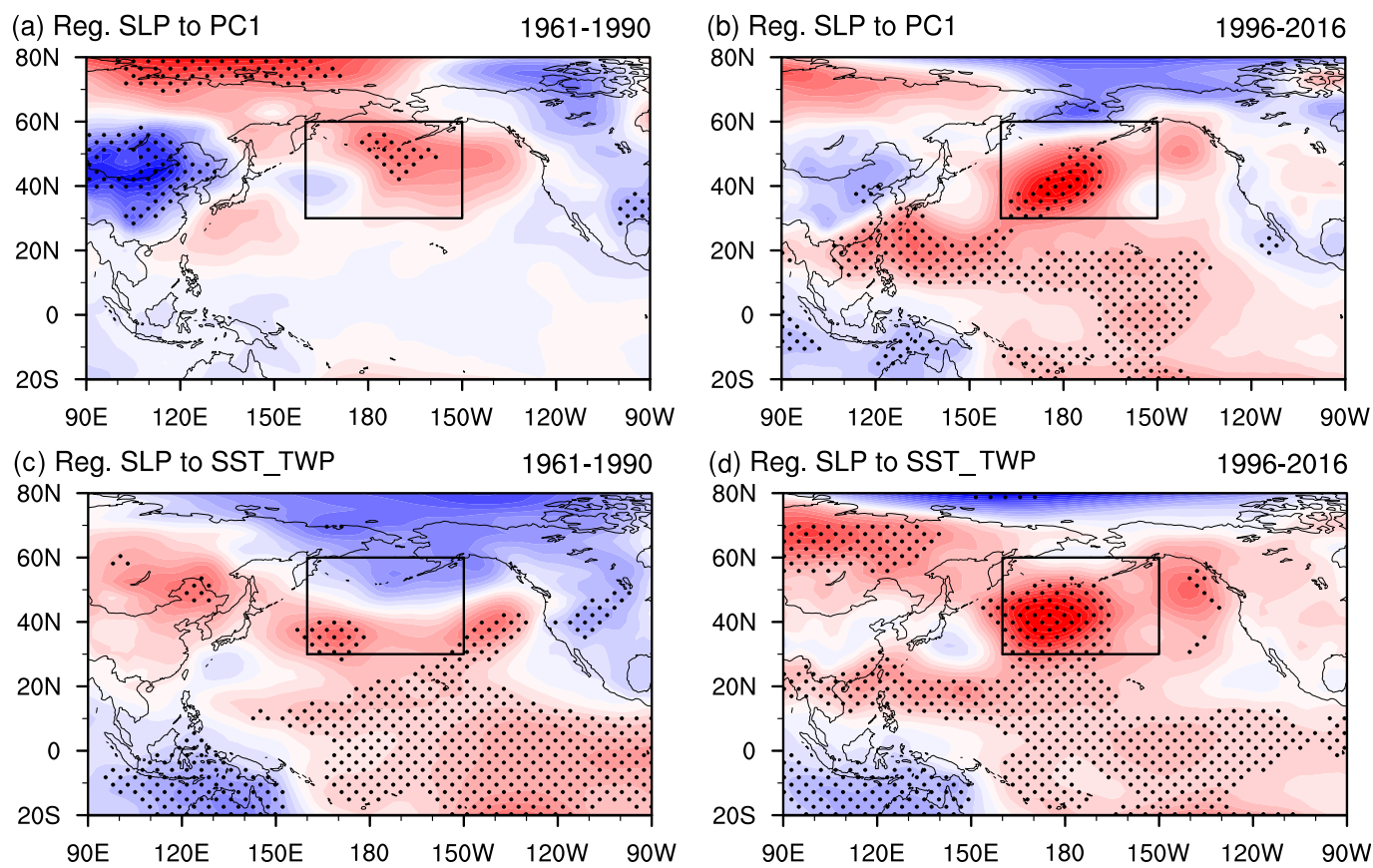

$$
\begin{array}{lllllllllllll}
-1.8 & -1.5 & -1.2 & -0.9 & -0.6 & -0.3 & 0 & 0.3 & 0.6 & 0.9 & 1.2 & 1.5 & 1.8
\end{array}
$$

FIG. 4. Linear regression pattern of midsummer sea level pressure (SLP; $\mathrm{mb} ; 1 \mathrm{mb}=1 \mathrm{hPa}$ ) against the PC1 index for (a) 1961-90 and (b) 1996-2016. (c),(d) As in (a) and (b), but for the SST_TWP index. Stippled areas indicate the values that significantly exceed the $95 \%$ confidence level, estimated using the Student's $t$ test. The black rectangular area represents the selected region for the Aleutian circulation index.

contributes to the intensification of the SST_TWPprecipitation relationship after the mid-1990s.

\section{Possible mechanisms}

\section{a. Westward expansion of the atmospheric circulation anomalies over the North Pacific}

The above result prompts interest in the reasons for the interdecadal change in the connection between the circulation anomalies over the central North Pacific/ Aleutian Islands region and the TWP SST. It is speculated that the interdecadal changes in background SST in the Pacific might be responsible for the changes in the atmospheric circulation anomalies. Previous studies have shown that the leading EOF mode of winter SST anomalies in the Pacific Ocean $\left(20^{\circ} \mathrm{S}-60^{\circ} \mathrm{N}\right)$ is dominated by the ENSO signal at the interannual time scale (Deser and Blackmon 1995; Zhang and Delworth 2007), while the second EOF mode reflects the North Pacific multidecadal oscillation (NPMO) at the multidecadal time scale (Zhang et al. 1996). EOF analysis is performed for midsummer SST in the Pacific Ocean $\left(20^{\circ} \mathrm{S}-\right.$ $\left.60^{\circ} \mathrm{N}, 120^{\circ} \mathrm{E}-80^{\circ} \mathrm{W}\right)$. The EOF1 mode shows the ENSO signature and its projection in the central-eastern North
Pacific, and the corresponding time series vary predominantly at the interannual time scale (Fig. S3). The EOF2 mode shows a strong SST signal in the westerncentral North Pacific (Fig. 5a). The corresponding time series (PC2_SST) vary dominantly at the interdecadal time scale (Fig. 5b). This mode is related to the NPMO mode, which is orthogonal to the EOF1 mode. As shown in Fig. 5b, there are four notable phase transitions in the $1900 \mathrm{~s}$, the mid-1940s, the mid-1960s, and the 1990s. Moreover, the NPMO is associated with dominant SLP anomalies over the North Pacific and northwest Pacific at midlatitudes (Fig. 5c). It is speculated that the recent

TABLE 1. Correlation coefficients between indices before and after the 1990s. One and two asterisks indicate values that significantly exceed the $90 \%$ and $95 \%$ confidence levels, respectively. Two asterisks and boldface indicate values that significantly exceed the $99 \%$ confidence level.

\begin{tabular}{lcc}
\hline \hline & $1961-90$ & $1996-2016$ \\
\hline Corr(PC1, SST_TWP) & 0.07 & $\mathbf{0 . 5 7} * *$ \\
Corr(PC1, Aleutian index) & $0.41^{* *}$ & $0.42^{*}$ \\
Corr(SST_TWP, Aleutian index) & 0.13 & $\mathbf{0 . 6 9} * *$ \\
Corr(SST_TWP, V index) & -0.01 & $\mathbf{0 . 4 9} * *$ \\
Corr(SST_TWP, VQ index) & 0.01 & $\mathbf{0 . 5 1} * *$ \\
\hline
\end{tabular}


(a) EOF2 SST JA

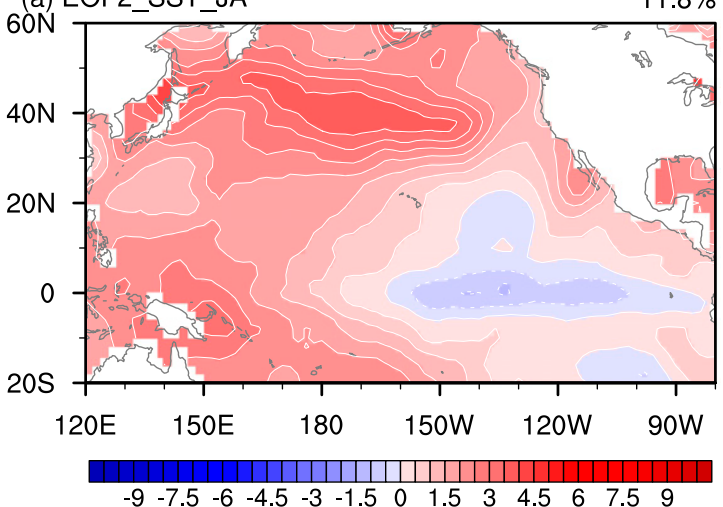

$\begin{array}{llllllllllllllll}-9 & -7.5 & -6 & -4 & 5 & -3 & -1.5 & 0 & 1.5 & 3 & 4.5 & 6 & 7.5 & 9\end{array}$

(c) Reg. SLP to PC2 SST

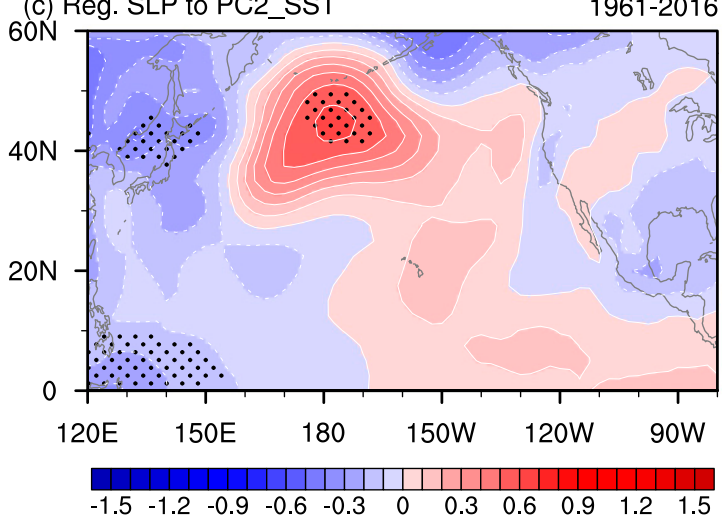

(b) PC2 SST

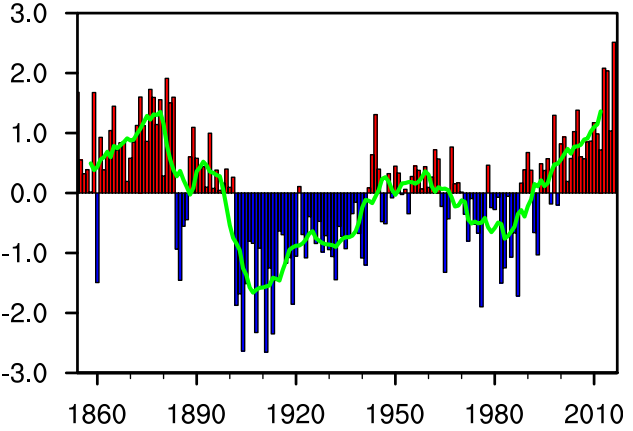

FIG. 5. (a) The second principal mode of midsummer SST in the Pacific Ocean $\left(20^{\circ} \mathrm{S}-60^{\circ} \mathrm{N}, 120^{\circ} \mathrm{E}-80^{\circ} \mathrm{W}\right)$, determined by EOF analysis. (b) The time series corresponding to the second mode (PC2_SST). The green lines represent the 9-yr sliding average. (c) Linear regression pattern of midsummer SLP (mb) against the PC2_SST for 1961-2016. Stippled areas indicate the values that significantly exceed the $90 \%$ confidence level, estimated using the Student's $t$ test.

shift of the NPMO may be associated with the changes in the atmospheric circulation over the North Pacific.

To examine the distinctive circulation anomalies over the North Pacific during different NPMO phases, the years characterized by a positive and a negative Aleutian index are selected for composite analysis in the two NPMO phases (Table 2). During the negative (positive) NPMO phase period, that is, 1961-90 (19962016), there are 16 (10) years with a positive Aleutian index and 14 (11) years with a negative Aleutian index. As illustrated in Fig. 6, a positive (negative) Aleutian index is accompanied by positive (negative) SLP anomalies over the North Pacific. When the NPMO is in a negative phase, the center of the SLP anomalies is at the east of the date line over the eastern North Pacific (Figs. 6a,b), which is in accord with the SLP anomalies related to the Aleutian index during P1 (Fig. 7a). However, when the NPMO is in a positive phase, the SLP anomalies extend westward and become centered at the west of the date line (Figs. 6c,d), consistent with the SLP anomalies related with the Aleutian index during P2 (Fig. 7c). These changes can be confirmed by the composite results of horizontal wind anomalies at $850 \mathrm{hPa}$ (Fig. S4). Accordingly, a positive Aleutian index coincides with anomalous divergent wind fields near the surface over the Northeast Pacific with a center of divergence at around $150^{\circ} \mathrm{W}$ during the negative NPMO phase (Fig. 7b). However, after the mid-1990s, the surface divergent wind anomalies expand over the centralwestern North Pacific, with a westward shift of the divergence center to the date line (Fig. 7d). It suggests that the shift of the NPMO to a positive phase contributes to the westward expansion of the circulation anomalies at the North Pacific after the mid-1990s, favorable to the enhanced connection of the circulation at the central North Pacific-Aleutian Islands region with the SST_TWP. 
TABLE 2. Years characterized by a positive or negative Aleutian circulation index during negative and positive NPMO phases, respectively.

\begin{tabular}{cccccc}
\hline \hline & \multicolumn{2}{c}{$1961-90$ is a negative NPMO phase period. } & & \multicolumn{2}{c}{ 1996-2016 is a positive NPMO phase period. } \\
\cline { 2 - 3 } \cline { 5 - 6 } & Positive Aleutian & Negative Aleutian & & Positive Aleutian & Negative Aleutian \\
\hline Years & $1961,1962,1963,1964,1966,1967$, & $1965,1968,1971,1972,1974$, & & $1996,1998,1999,2000,2001$, & $1997,2002,2004,2005$, \\
& $1969,1970,1973,1980,1981,1982$, & $1975,1976,1977,1978,1979$, & & $2003,2006,2010,2012,2016$ & $2007,2008,2009,2011$, \\
& $1983,1984,1985,1989$ & $1986,1987,1988,1990$ & & & $2013,2014,2015$ \\
Total & 16 & 14 & 10 & 11 \\
\hline
\end{tabular}

\section{b. Enhanced relationship between the TWP SST anomalies and midlatitude circulation anomalies}

Frankignoul and Sennécheal (2007) detected that the influence of the North Pacific SST anomalies on the large-scale atmospheric circulation, which is significant during late summer and early winter, involves the wavelike propagation in the middle and upper troposphere. Actually, the NPMO are in a positive phase during winter and summer after the 1990s (Fig. S5), which could affect the propagation of the Rossby wave at midlatitudes. Therefore, the linear regression of 200$\mathrm{hPa}$ meridional wind (V200; shaded) and wave activity flux (WAF; vectors) with regard to the SST_TWP index are investigated (Fig. 8). The WAF, which is computed according to Plumb's formulation (Plumb 1985), can depict the propagation of stationary Rossby waves. One of the conspicuous features is the alternation of significant northerly and southerly anomalies over the region stretching from the TWP to China and on to the North Pacific during P2 (Fig. 8b). Comparatively, the meridional wind anomalies are insignificant over East Asia and the western-to-central North Pacific during P1 (Fig. 8a). Additionally, anomalous wave trains originate from the west Pacific, propagate northeastward to the northwest Pacific, and then extend eastward over the North Pacific during P2 (Fig. 8b), which is weak before the 1990s (Fig. 8a). This supports the westward and poleward extension of the SST_TWP-related atmospheric circulation anomalies over the midlatitudes of the North Pacific in the latter period (Fig. 4d).
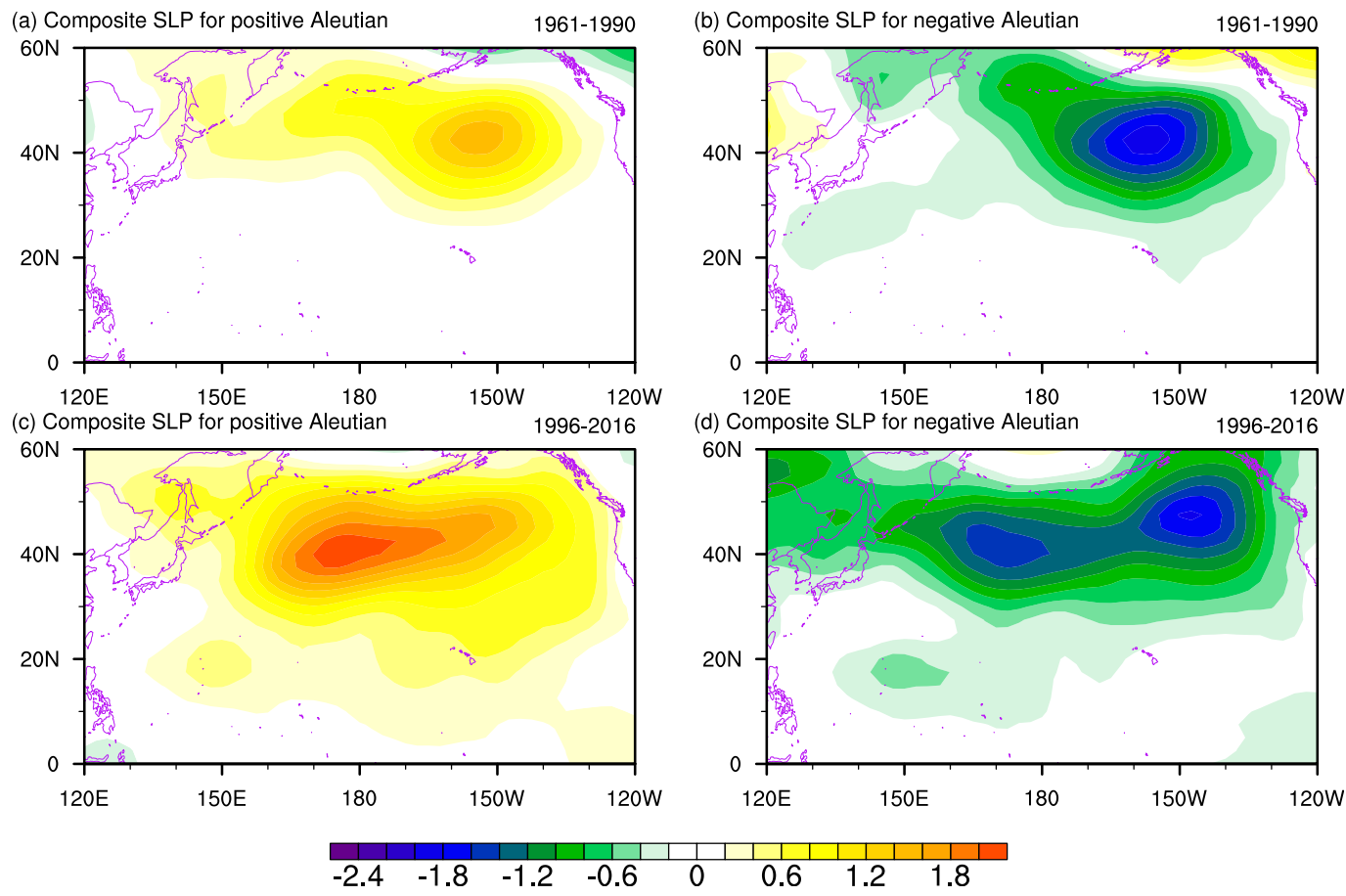

FIG. 6. Composite of SLP anomalies (mb) relative to the climatology for (a) positive Aleutian circulation index during 1961-90, (b) negative Aleutian circulation index during 1961-90, (c) positive Aleutian circulation index during 1996-2016, and (d) negative Aleutian circulation index during 1996-2016. The climatology is the average during 1961-2016. 
(a) Reg. SLP to Aleutian index
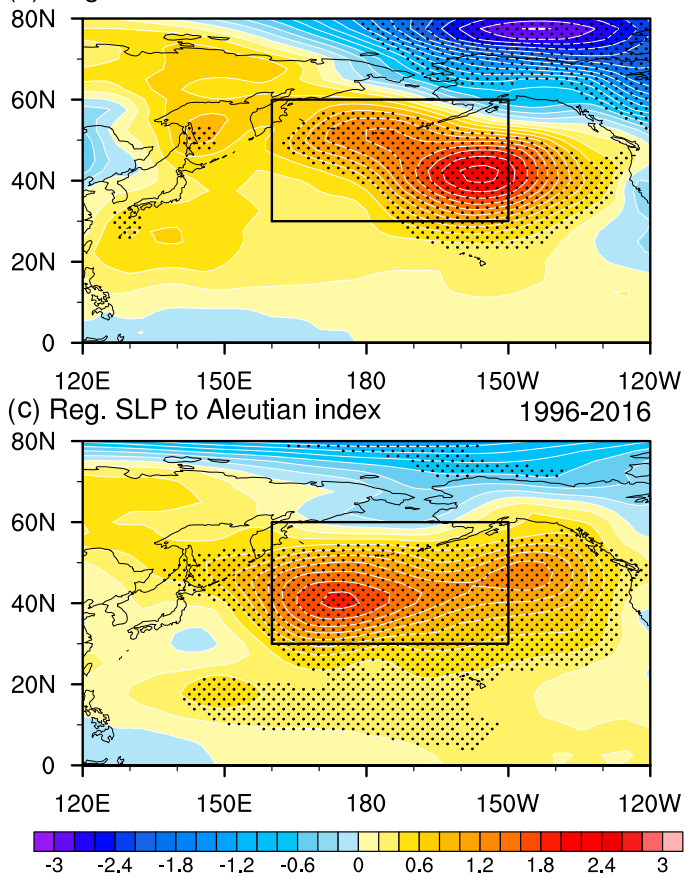

(b) Reg. Sfc. Div. Wind to Aleutian index 1961-1990

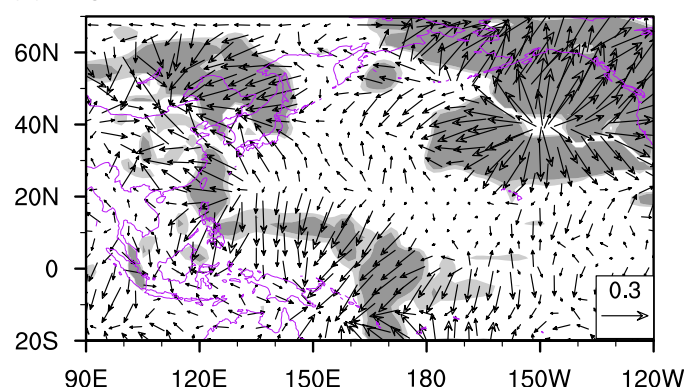

(d) Reg. Sfc. Div. Wind to Aleutian index 1996-2016

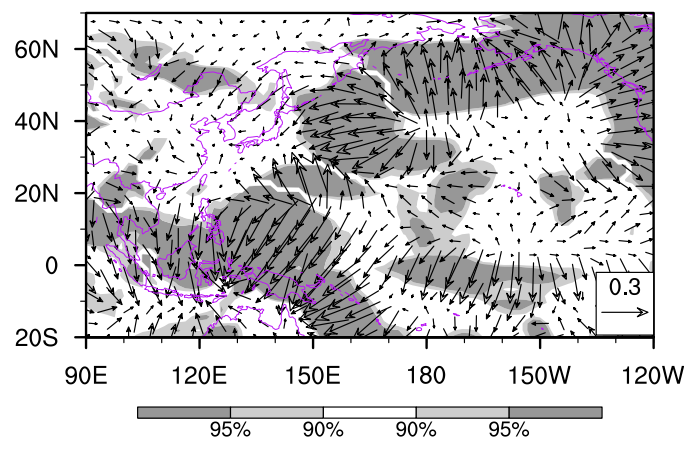

FIG. 7. Linear regression pattern of midsummer (left) SLP (mb) and (right) surface divergent wind component $\left(\mathrm{m} \mathrm{s}^{-1}\right)$ against the Aleutian circulation index for (a),(b) 1961-90 and (c),(d) 1996-2016. Stippled areas indicate the values that significantly exceed the 95\% confidence level, estimated using the Student's $t$ test. The black rectangular area in (a) and (c) represents the selected region for the Aleutian circulation index.

Furthermore, in response to warming SST anomalies are positive height anomalies in the tropical centraleastern Pacific and negative anomalies in the Maritime Continent, along with dominance of positive anomalies over the North Pacific and Northeast Asia (Figs. 9a,b). Moreover, profound easterly anomalies prevail over the equatorial Pacific near the surface because of the zonal thermal gradients, and turn to be southerly or southwesterly over the northern region. It is notable that the positive height anomalies over the midlatitude North Pacific become quantitatively larger and expand poleward to Aleutian Islands during P2. In addition, both the positive height and easterlies anomalies at the equatorial Pacific expand westward to the Indo-China Peninsula during P2. The anomalous anticyclone over the western Pacific is centered west of the Philippines during P1, but moves westward and northward to the subtropical northwest Pacific in the latter period. Accordantly, the upper-level zonal wind anomalies associated with the positive SST_TWP are constrained over the central-to-eastern Pacific during P1 (Fig. 9c). Nonetheless, after the mid-1990s, the westerly anomalies extend westward to the Maritime Continent, along with a southwest-northeast-oriented wavelike pattern of zonal wind anomalies over the region stretching from
South China to the Aleutian Islands (Fig. 9d). Westerly and easterly anomalies straddle the Aleutian Islands, consistent with the positive SLP anomalies (Fig. 4d). These results suggest an intensified connection between the SST TWP and the circulation anomalies over the central North Pacific-Aleutian Islands region after the mid-1990s.

Furthermore, the anomalous easterlies at the tropics extend westward to Southeast Asia after the mid-1990s, and the anticyclonic anomaly shifts from the centralwestern Pacific for P1 to South China for P2 (Figs. 9a,b). Moreover, a a cyclone and anticyclone pair is centered over Japan and the North Pacific in the latter period, respectively (Fig. 9b). These changes in the SST_TWPassociated circulation anomalies can exert an intensified impact on moisture transport over East China. Moisture transport plays a vital role in precipitation processes, and southeasterly or southwesterly transport of water vapor makes a predominant contribution to summer precipitation over China (Zhou and Wang 2006; Li et al. 2012; Li and Zhou 2012; Sun and Wang 2014b). Han et al. (2015) revealed that the recent decrease in NEC summer precipitation has occurred concurrently with a reduction of moisture content in situ. Hence, the related moisture transport and lower-layer horizontal wind anomalies are explored in this section. 
(a) Reg.V200 / WAF200 to SST_TWP
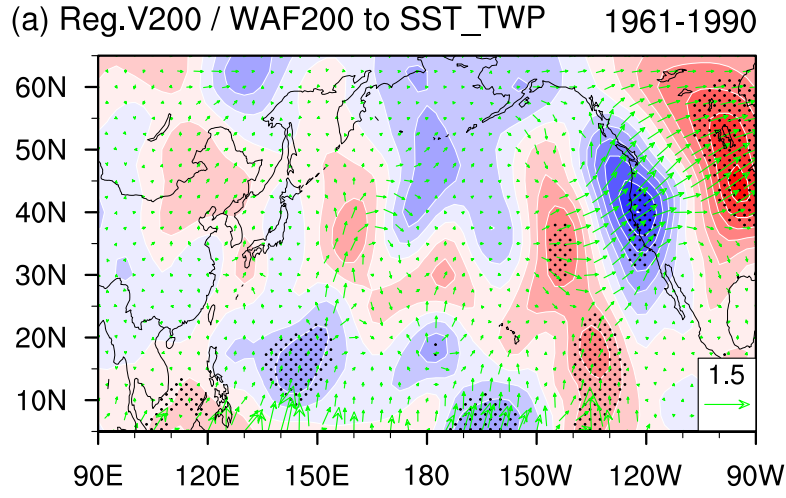

(b) Reg.V200 / WAF200 to SST_TWP

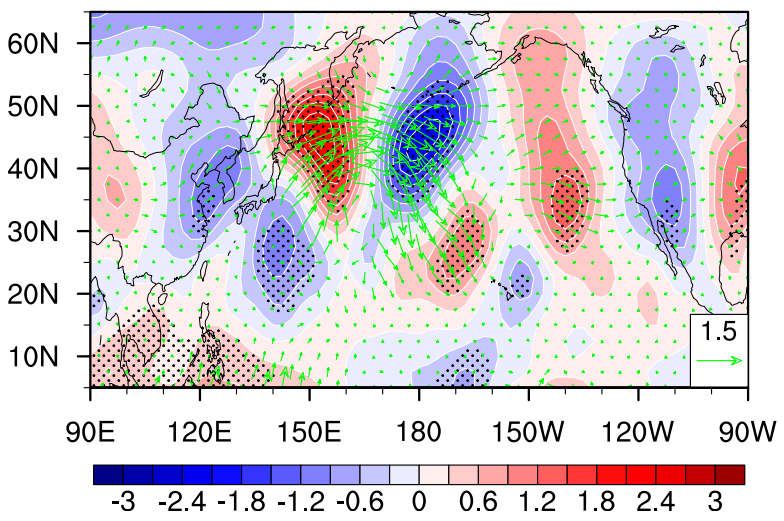

FIG. 8. Linear regression pattern of midsummer meridional wind $\left(\mathrm{m} \mathrm{s}^{-1}\right.$; shaded) and wave activity flux $\left(\mathrm{m}^{2} \mathrm{~s}^{-2}\right.$; vectors) at $200 \mathrm{hPa}$ with regard to the SST_TWP index for (a) 1961-90 and (b) 19962016. Stippled areas indicate the values that significantly exceed the $95 \%$ confidence level, estimated using the Student's $t$ test.

During $\mathrm{P} 1$ and $\mathrm{P} 2$, positive precipitation anomalies over NEC are coincident with an anomalous cyclonic wind field centered over eastern Mongolia and an anticyclonic wind field centered over the subtropical northwest Pacific (Figs. 10a,b). The peripheral southwesterly flow of the anticyclone transports water vapor from the tropical seas northward to NEC across the southern boundary (Figs. 10c,d), dominantly contributing to the EOF1 mode of midsummer precipitation over NEC (Han et al. 2019a). Additionally, anomalous convergence of moisture is present over Mongolia with NEC located at its leading edge. The westerly conveys water vapor from inland areas into NEC across the western boundary, which plays a lesser role in NEC summer precipitation (Han et al. 2019a). It is notable that there is an anomalous convergence centered over the northwest Pacific during P2 (Fig. 10b). The easterly on the northern flank transports water vapor from the northwest Pacific to NEC across the eastern boundary (Fig. 10d).

Prior to the 1990s, a positive SST_TWP index is coherent with the dominance of anomalous anticyclonic wind and moisture divergence west of the Philippines and with a cyclone and moisture convergence south of Japan (Figs. 10e,g). The wind fields anomalies and moisture flux are weak over China. After the mid-1990s, dramatic changes occur with the westward extension of the anomalous anticyclone over southern China. The southwesterly on the western flank of this anticyclone occupies eastern China, transporting water vapor from the tropical seas northward (Figs. 10f,h). It can also be observed that remarkable anomalous cyclonic wind and moisture convergence are centered over the northwest Pacific. The easterly flow on the northern flank transports water vapor from the northwest Pacific westward to NEC, which is in accordance with the anomalies associated with the EOF1 mode.

To explore the intensified relationship of the SST TWP and moisture transport over eastern China, a meridional wind index ( $V$ index) is calculated as the area-weighted average of meridional wind over East China $\left(20^{\circ}-35^{\circ} \mathrm{N}, 105^{\circ}-120^{\circ} \mathrm{E}\right)$ and a meridional moisture index (VQ index) is defined as the area-weighted mean of vertically integrated meridional moisture transport over East China. In-phase covariability between the SST_TWP and V indices does not become significant until the 1990s; that is, their correlation coefficient increases from -0.01 during P1 (insignificant) to 0.49 (above the $99 \%$ confidence level) during P2. Consistently, the correlation coefficient between the SST_TWP and VQ indices is only 0.01 (insignificant) before the 1990s but 0.51 (above the $99 \%$ confidence level) thereafter. These results suggest the SST anomaly in the TWP exerts an influence on the EOF1 pattern of NEC precipitation through modulating the meridional wind and moisture transport over eastern China after the mid-1990s.

To illustrate the anomalous dynamic processes associated with the SST_TWP, Fig. 11 shows the anomalous divergence and vertical wind associated with the SST TWP index. For both subperiods, warming SST anomalies induce prominent convergent anomalies in the lower-middle troposphere and divergence in the upper troposphere, which excite marked anomalies of ascending motion in situ. Comparatively, the anomalous ascent is stronger during $\mathrm{P} 2$ than P1. After the mid1990s, the tropical air rises to the upper troposphere and moves northward before sinking, representing a local closed circulation over the Maritime Continent (Fig. 11b). However, during P1, the local closed circulation is weaker and confined to the lower layers (Fig. 11a). Consequently, significant abnormal convergence occurs at South China Sea in the upper level and divergence appears in the lower level during P2, which are not present during P1. Near the surface, the descending air masses are deflected southward 
(a) Reg. Z1000 / sfc. wind to SST TWP 1961-1990

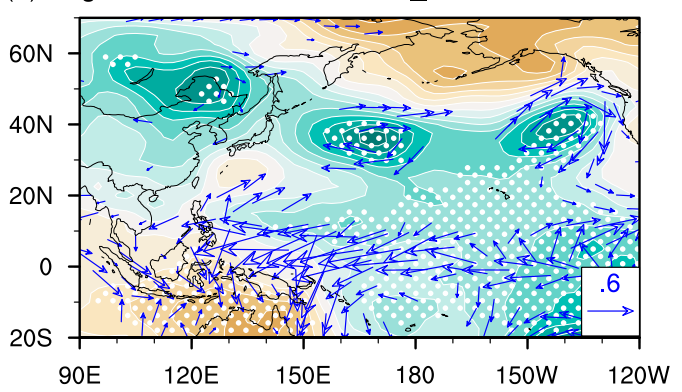

(b) Reg. Z1000 / sfc. wind to SST_TWP 1996-2016

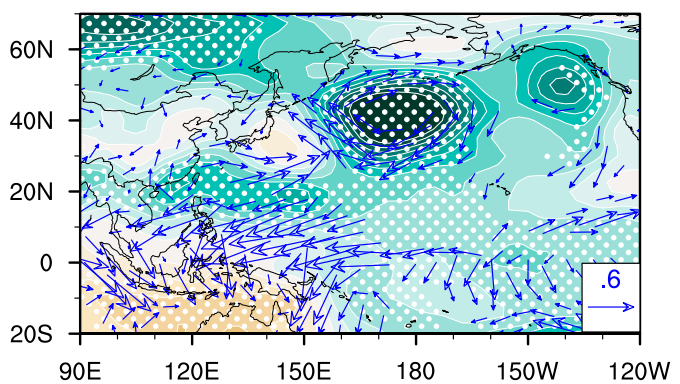

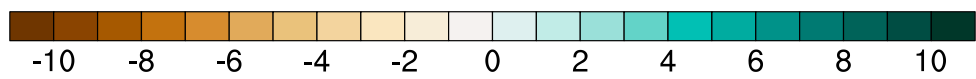

(c) Reg. U200 to SST_TWP 1961-1990

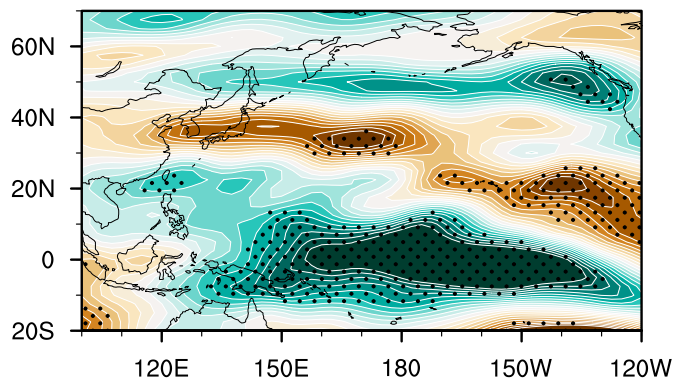

(d) Reg. U200 to SST_TWP

1996-2016

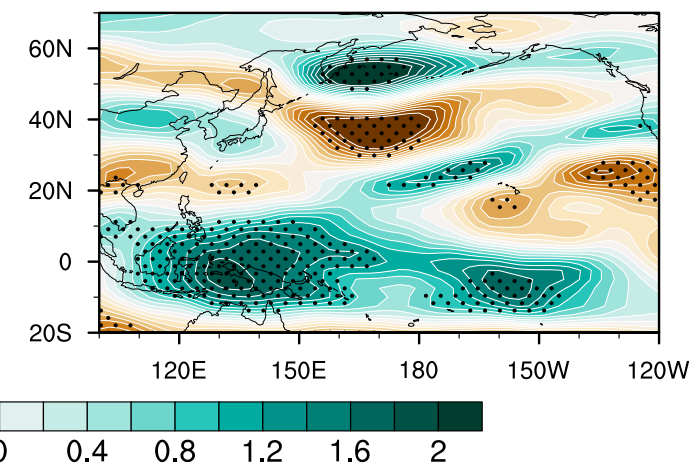

FIG. 9. Linear regression pattern of midsummer (a),(b) near-surface horizontal wind ( $\mathrm{m} \mathrm{s}^{-1}$; vectors) and $1000 \mathrm{hPa}$ geopotential height (m; shaded) and (c),(d) zonal wind at $200 \mathrm{hPa}$ (unit: $\mathrm{m} \mathrm{s}^{-1}$ ) with regard to the SST_ TWP index for (left) 1961-90 and (right) 1996-2016. Stippled areas indicate the values that significantly exceed the 95\% confidence level, estimated using the Student's $t$ test.

over the Maritime Continent and northward over eastern China, consistent with the anomalous southerly and strengthened meridional moisture transport over East China (Figs. 10f,h).

\section{Conclusions and discussion}

This study investigates temporal variations in the connection between the leading EOF mode of NEC midsummer precipitation and simultaneous SST anomalies in the tropical west Pacific for 1961-2016. We observed a dramatically different correlation distribution in the TWP. The SST_TWP exhibits a significant positive correlation with the EOF1 mode of precipitation after the mid-1990s, whereas the relationship is statistically insignificant during 1961-90. Further results indicate that the NPMO shifts to a positive phase around the 1990s. This is accompanied by the westward extension of the circulation anomalies from the northeast Pacific to the central North Pacific-Aleutian Islands region, but also by the SST_TWP-associated wave trains that originate from the west Pacific and propagate northeastward to the midlatitude region of the North Pacific after the mid-1990s (Fig. 12). The latter induces the poleward expansion and intensification of the SST TWP-associated circulation anomalies, connecting the SST_TWP and the circulation anomalies over the central North Pacific-Aleutian Islands region. Additionally, the atmospheric circulation anomalies over the central North Pacific-Aleutian Islands region exhibit an intimate relationship with the EOF1 mode of NEC precipitation during the whole period. Therefore, the SST_TWP has a close linkage with NEC precipitation after the mid-1990s.

Moreover, the tropical anticyclone/cyclone related to the SST_TWP expands westward to South China and exerts an intensified impact on meridional wind anomalies and moisture transport over East China after the mid-1990s. Specifically, the lower-level convergent and upper-level divergent anomalies caused by warming SST anomalies lead to anomalous ascending movement over the Maritime Continent, which strengthens and expands northward during $\mathrm{P} 2$. The rising air masses turn northward before sinking, representing a local closed 

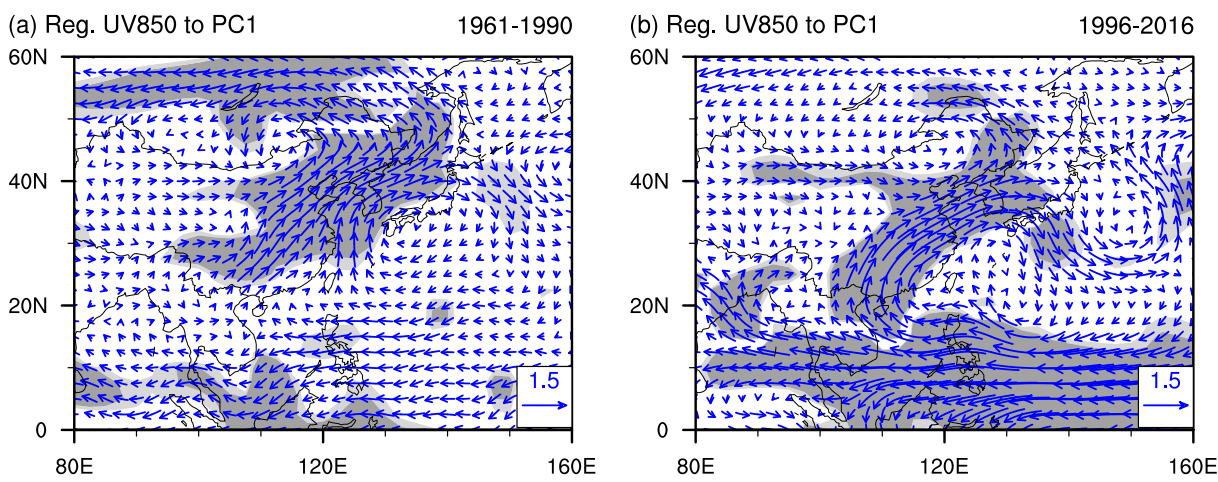

(c) Reg. Moisture flux to PC1 1961-1990
(d) $\mathrm{R}$
(d) Reg. Moisture flux to PC1
1996-2016
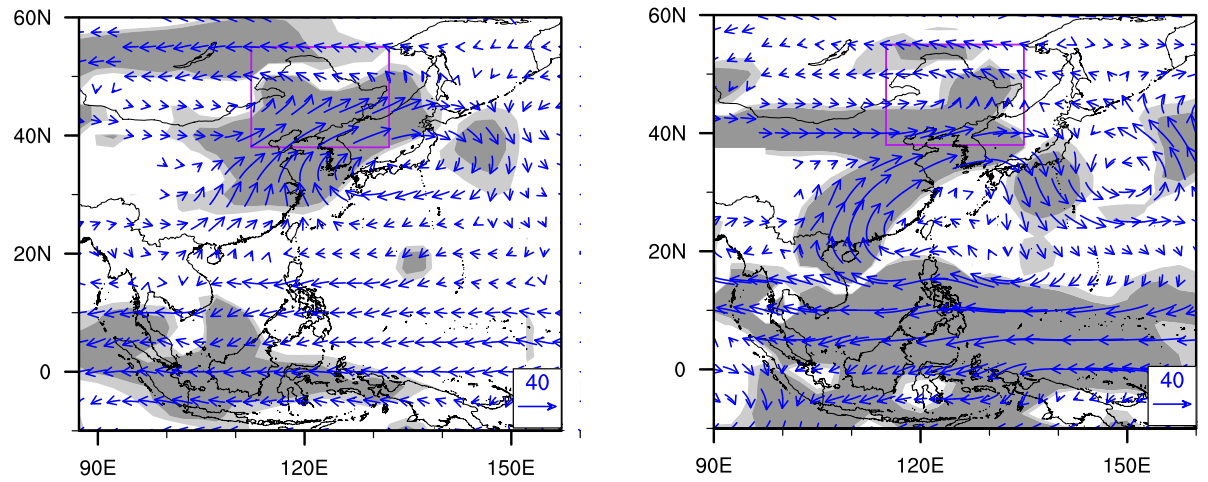

(e) Reg. UV850 to SST_TWP 1961-1990

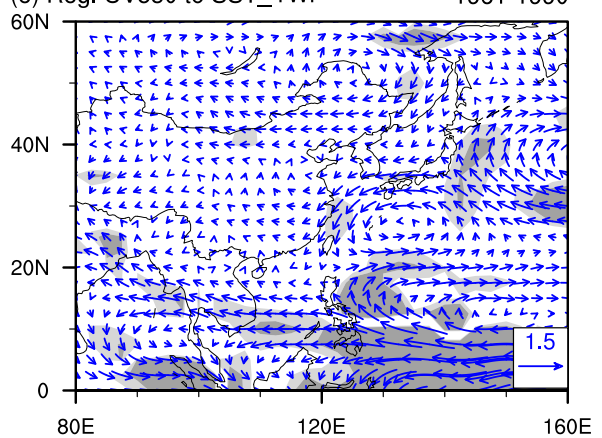

(f) Reg. UV850 to SST_TWP

1996-2016

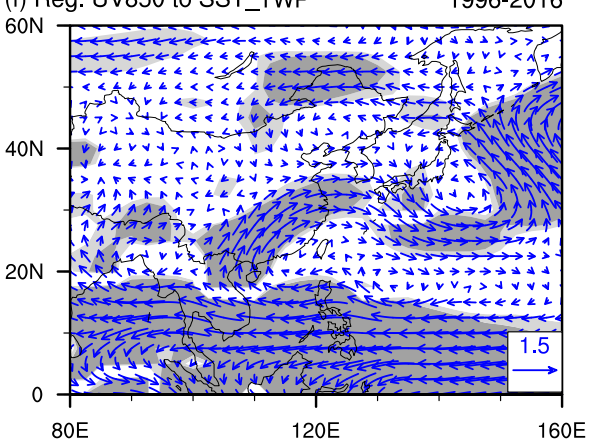

(g) Reg. Moisture flux to SST_TWP 1961-1990

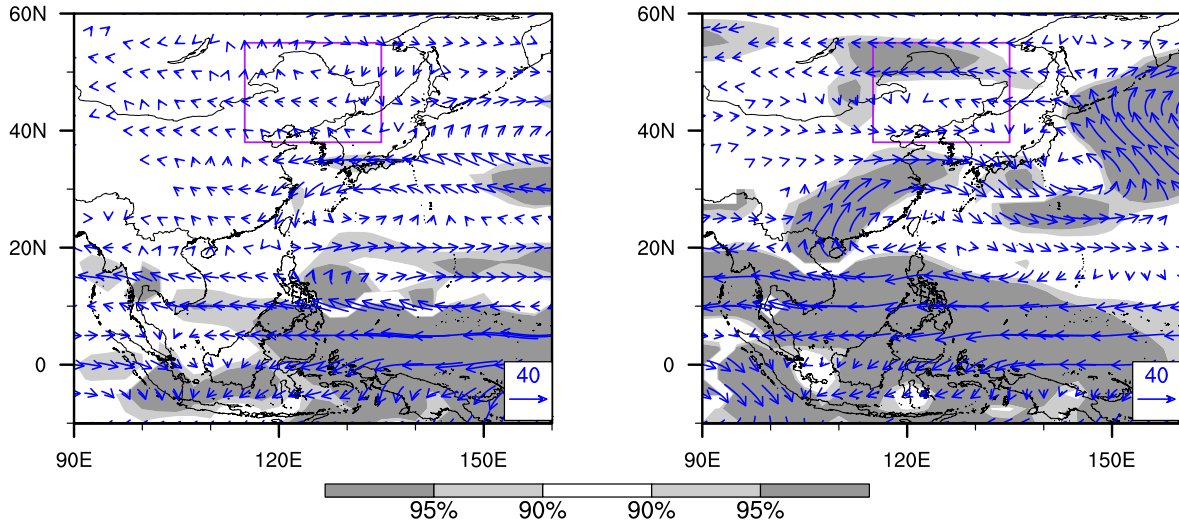

FIG. 10. Linear regression pattern of midsummer (a),(b) horizontal wind at $850 \mathrm{hPa}\left(\mathrm{m} \mathrm{s}^{-1}\right)$ and (c),(d) vertically integrated moisture flux from the surface to $300 \mathrm{hPa}\left(\mathrm{kg} \mathrm{m}^{-1} \mathrm{~s}^{-1}\right)$ with regard to the PC1 index for (left) 1961-90 and (right) 1996-2016. (e)-(h) As (a)-(d), but with regard to the SST_TWP index. Dark (light) shading indicates values that significantly exceed the $95 \%$ (90\%) confidence level, estimated using the Student's $t$ test. 
(a) Reg. (SST_TWP \& Div, V \& Omega) $100^{\circ}-120^{\circ} \mathrm{E}$

1961-1990

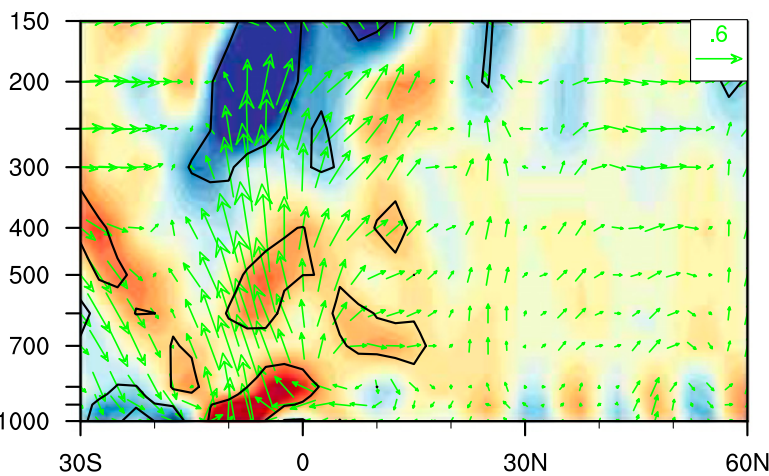

(b) Reg. (SST_TWP \& Div, V \& Omega) $100^{\circ}-120^{\circ} \mathrm{E} \quad 1996-2016$

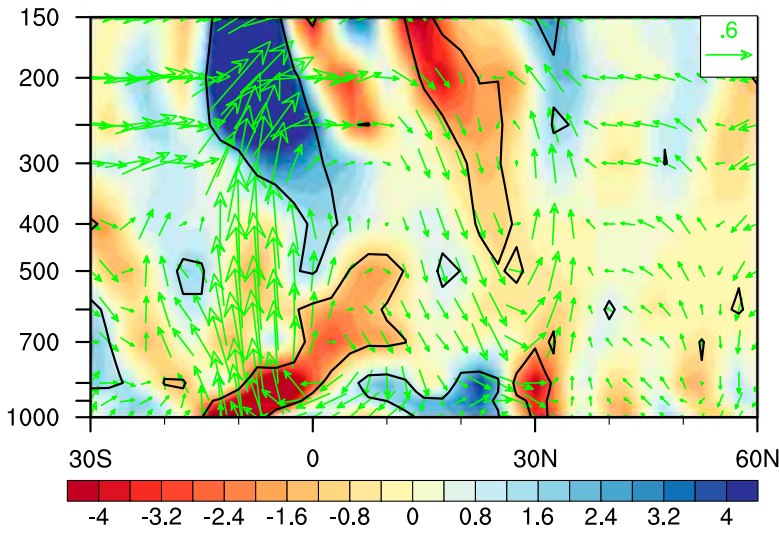

FIG. 11. Vertical-horizontal cross section averaged within $100^{\circ}-$ $120^{\circ} \mathrm{E}$ for vertical wind (vectors; $\mathrm{m} \mathrm{s}^{-1}$ for meridional wind and $-10^{-2} \mathrm{~Pa} \mathrm{~s}^{-1}$ for omega) and divergence (shading; $10^{-7} \mathrm{~s}^{-1}$ ) anomalies during midsummer regressed onto the SST_TWP index: (a) 1961-90 and (b) 1996-2016. Divergence anomalies enclosed by black contours are at the $90 \%$ confidence level based on the Student's $t$ test.

circulation over the Maritime Continent. Furthermore, near the surface, the descending branch of the local cell is deflected equatorward over the South China Sea and northward over East China. Thus, warming SST anomalies are coincident with dominant southerly anomalies as well as enhanced moisture transport over eastern China during P2. In addition, in response to the positive SST_TWP, the easterly anomalies at the northern flank of the anomalous cyclone centered over Japan transport moisture from the northwest Pacific to NEC across the eastern boundary. These conditions contribute to the strengthened relationship between the SST_TWP and the EOF1 mode of NEC midsummer precipitation after the mid-1990s.

In addition, it should be noted that the western extension of the circulation anomalies over the North Pacific and the changes in the SST_TWP-associated circulation anomalies after the mid-1990s can also be obtained based on the fifth-generation ECMWF

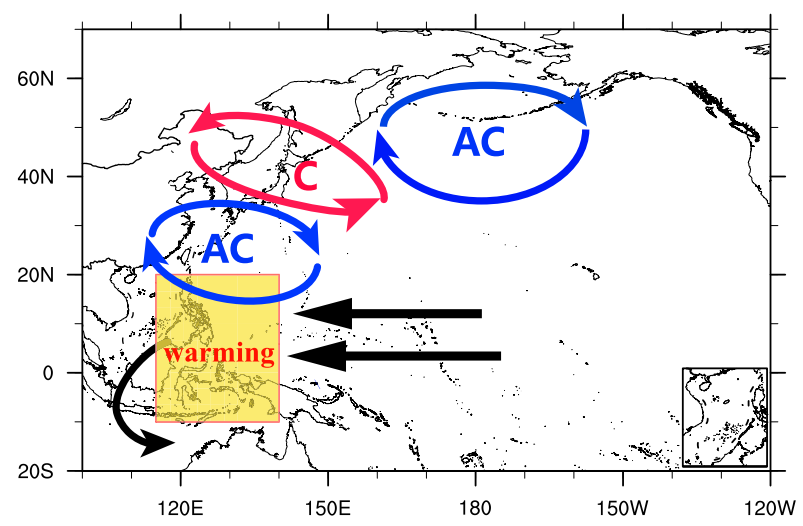

FIG. 12. Schematic diagram of the lower-level circulation anomalies associated with warming SST anomalies in the tropical west Pacific. Cold SST anomalies correspond to an opposite case. $\mathrm{AC}$ indicates anticyclone and $\mathrm{C}$ indicates cyclone. Arrows indicate horizontal winds.

atmospheric reanalysis dataset (Figs. S6-S9). It suggests that the results in the present study are robust.

It is well recognized that there were substantial atmospheric and oceanographic changes around 1976/77 (Ding et al. 2013), termed the $1976 / 77$ climate shift. The precipitation regime in eastern China has experienced an obvious shift in the middle and late 1970s (Ding et al. 2008). However, the SST_TWP-related precipitation anomalies are hardly significant at most NEC stations both before and after the climate shift (Fig. S10), implying that the 1976/77 climate shift had little influence on the SST_TWP-precipitation relationship.

In addition, warming SST anomalies in the TWP is coherent with anomalous anticyclonic wind anomalies and moisture divergence over the west Pacific during both periods (Figs. 10e-h). Comparatively, the anticyclone and moisture divergence extend westward over South China and become intensified in the latter period, along with anomalous southerly current over East China. It implies that the East Asian circulation anomalies associated with the SST_TWP have experienced a significant decadal change around the 1990s. This result is consistent with Kwon et al. (2005) and Yim et al. (2008), who documented a strengthened relationship between the East Asian and the western North Pacific summer monsoons. Moreover, these changes may be attributed to warming in the TWP. As documented by H. Gao et al. (2014), in the global warming, the SST in the tropical west Pacific exhibits a striking warming trend after the 1990s, which facilitates the intensification and westward extension of the west Pacific subtropical high.

Moreover, the NPMO is the component of the Pacific decadal oscillation (PDO) that is linearly independent of ENSO (Deser and Blackmon 1995). The NPMO is 
equivalent to the PDO when the ENSO signal is removed (Zhang et al. 1996), and it is dominated by multidecadal variability (Zhang and Delworth 2007). Moreover, analysis of observations and numerical simulations suggested that the Atlantic multidecadal oscillation (AMO) fluctuations contribute to the NPMO through atmospheric teleconnections and oceanic dynamics (Zhang and Delworth 2007). Therefore, the AMO needs to be considered along with the forcing for the North Pacific climate change. Furthermore, the PDO and AMO can also modulate interannual climate variation (Zhu et al. 2011, 2015). For example, the relationship between ENSO and East Asian monsoon systems is regulated by interdecadal signals (Wang 2002; He and Wang 2013). Zhang et al. (2018) pointed out that when the PDO and AMO are out of phase, the samesigned SST anomalies in the North Pacific and in the North Atlantic lead to a meridional tripole mode of summer precipitation at East China through a circumglobal teleconnection wave, and that when the PDO and AMO are in phase, the SST anomalies causes a meridional dipole mode of summer precipitation via a teleconnection wave train along the great circle route. The modulation of the PDO and AMO on the atmospheric circulation and precipitation patterns over the East Asia and the west Pacific is complicated and diverse (Lu et al. 2006; Wang et al. 2008; Zhu et al. 2015; Hao and He 2017). The interesting issue deserves further exploration but is beyond the scope of the present study.

Acknowledgments. We very much appreciate the comments by the three anonymous reviewers and the editor, Dr. Yi Deng. These comments led to a significant improvement in the manuscript. This work was jointly supported by the National Key Research and Development Program of China (Grant 2016YFA0600703), the National Natural Science Foundation of China (Grants 41805046, 41875118, and 41875119), and the State Scholarship Fund by China Scholarship Council (Grant 201908320172).

\section{REFERENCES}

Bai, R. H., 2001: Relation between sea surface temperature anomaly in the Atlantic and summer precipitation over the Northeast China. Mar. Forecasts, 18, 50-57.

Becker, A., P. Finger, A. Meyer-Christoffer, B. Rudolf, K. Schamm, U. Schneider, and M. Ziese, 2012: A description of the global landsurface precipitation data products of the Global Precipitation Climatology Centre with sample applications including centennial (trend) analysis from 1901-present. Earth Syst. Sci. Data Discuss., 5, 921-998, https://doi.org/10.5194/essdd-5-921-2012.

Cao, F., T. Gao, L. Dan, Z. Ma, X. Yang, and F. Yang, 2018: Contribution of large-scale circulation anomalies to variability of summer precipitation extremes in northeast China. Atmos. Sci. Lett., 19, e867, https://doi.org/10.1002/asl.867.
Cao, J., R. Y. Lu, J. M. Hu, and H. Wang, 2013: Spring Indian Ocean-western Pacific SST contrast and the East Asian summer rainfall anomaly. Adv. Atmos. Sci., 30, 1560-1568, https://doi.org/10.1007/s00376-013-2298-6.

Chang, C.-P., Y. S. Zhang, and T. Li, 2000: Interannual and interdecadal variations of the East Asian summer monsoon and tropical Pacific SSTs. Part I: Role of the subtropical ridge. J. Climate, 13, 4310-4325, https://doi.org/10.1175/1520-0442(2000) 013<4310:IAIVOT>2.0.CO;2.

Deng, K., S. Yang, A. Lin, C. Li, and C. Hu, 2019: Unprecedented East Asian warming in spring 2018 linked to the North Atlantic tripole SST mode. Atmos. Oceanic Sci. Lett., 12, 246253, https://doi.org/10.1080/16742834.2019.1605807.

Deser, C., and M. L. Blackmon, 1995: On the relationship between tropical and North Pacific sea surface temperature variations. J. Climate, 8, 1677-1680, https://doi.org/10.1175/1520-0442(1995) $008<1677$ :OTRBTA $>2.0$. CO;2.

Ding, H., R. J. Greatbatch, M. Latif, W. Park, and R. Gerdes, 2013: Hindcast of the 1976/77 and 1998/99 climate shifts in the Pacific. J. Climate, 26, 7650-7661, https://doi.org/10.1175/ JCLI-D-12-00626.1.

Ding, Y. H., Z. Y. Wang, and Y. Sun, 2008: Inter-decadal variation of the summer precipitation in East China and its association with decreasing Asian summer monsoon. Part I: Observed evidences. Int. J. Climatol., 28, 1139-1161, https://doi.org/ 10.1002/joc. 1615 .

Feng, X., X. Wang, and Y. Wang, 2006: Anomalies of the Northeast China floods season precipitation and SVD analysis with SSTA in world oceans. J. Trop. Meteor., 22, 367-373.

Feng, Y., and H. P. Chen, 2016: Warming over the North Pacific can intensify snow events in Northeast China. Atmos. Oceanic Sci. Lett., 9, 122-128, https://doi.org/10.1080/16742834.2016.1133072.

Frankignoul, C., and N. Sennécheal, 2007: Observed influence of North Pacific SST anomalies on the atmospheric circulation. J. Climate, 20, 592-606, https://doi.org/10.1175/JCLI4021.1.

Gao, H., W. Jiang, and W. J. Li, 2014: Changed relationships between the East Asian summer monsoon circulations and the summer rainfall in eastern China. J. Meteor. Res., 28, 10751084, https://doi.org/10.1007/s13351-014-4327-5.

Gao, Y., H. J. Wang, and D. Chen, 2017: Interdecadal variations of the South Asian summer monsoon circulation variability and the associated sea surface temperatures on interannual scales. Adv. Atmos. Sci., 34, 816-832, https://doi.org/10.1007/s00376017-6246-8.

Gao, Z., Z.-Z. Hu, J. Zhu, S. Yang, R.-H. Zhang, Z. Xiao, and B. Jha, 2014: Variability of summer rainfall in Northeast China and its connection with spring rainfall variability in the HuangHuai region and Indian Ocean SST. J. Climate, 27, 7086-7101, https://doi.org/10.1175/JCLI-D-14-00217.1.

Han, T., H. Chen, and H Wang, 2015: Recent changes in summer precipitation in Northeast China and the background circulation. Int. J. Climatol., 35, 4210-4219, https://doi.org/10.1002/ joc. 4280 .

— , H. Wang, and J. Sun, 2017: Strengthened relationship between eastern ENSO and summer precipitation over Northeast China. J. Climate, 30, 4497-4512, https://doi.org/ 10.1175/JCLI-D-16-0551.1.

— S. He, X. Hao, and H. Wang, 2018a: Recent interdecadal shift in the relationship between Northeast China's winter precipitation and the North Atlantic and Indian Oceans. Climate Dyn., 50, 1413-1424, https://doi.org/10.1007/s00382-017-3694-x.6

,,-- H. Wang, and X. Hao, 2018b: Enhanced influence of early-spring tropical Indian Ocean SST on the following 
early-summer precipitation over Northeast China. Climate Dyn., 51, 4065-4076, https://doi.org/10.1007/s00382-017-3669-y.

,,--- , and $\longrightarrow, 2019$ a: Variation in principal modes of midsummer precipitation over Northeast China and its associated atmospheric circulation. Adv. Atmos. Sci., 36, 55-64, https://doi.org/10.1007/s00376-018-8072-z.

$\longrightarrow$, H. Wang, X. Hao, and S. Li, 2019b: Seasonal prediction of midsummer extreme precipitation days over Northeast China. J. Appl. Meteor. Climatol., 58, 2033-2048, https://doi.org/ 10.1175/JAMC-D-18-0253.1.

Hao, X., and S. He, 2017: Combined effect of ENSO-like and Atlantic multidecadal oscillation SSTAs on the interannual variability of the East Asian winter monsoon. J. Climate, 30, 2697-2716, https://doi.org/10.1175/JCLI-D-16-0118.1.

He, J. H., Z. W. Wu, L. Qi, and A. J. Jiang, 2006: Relationships among the Northern Hemisphere annual mode, the Northeast cold vortex and the summer rainfall in Northeast China. J. Meteor. Environ., 22, 1-5.

He, S. P., and H. J. Wang, 2013: Oscillating relationship between the East Asian winter monsoon and ENSO. J. Climate, 26, 9819-9838, https://doi.org/10.1175/JCLI-D-13-00174.1.

Hu, Z.-Z., S. Yang, and R. Wu, 2003: Long-term climate variations in China and global warming signals. J. Geophys. Res., $\mathbf{1 0 8}$, 4614, https://doi.org/10.1029/2003JD003651.

Huang, B., and Coauthors, 2017: Extended Reconstructed Sea Surface Temperature version 5 (ERSSTv5), Upgrades, validations, and intercomparisons. J. Climate, 30, 8179-8205, https://doi.org/10.1175/JCLI-D-16-0836.1.

Huangfu, J.-L., R.-H. Huang, and W. Chen, 2015: Influence of tropical western Pacific warm pool thermal state on the interdecadal change of the onset of the South China Sea summer monsoon in the late-1990s. Atmos. Oceanic Sci. Lett., 8, 95-99, https://doi.org/10.3878/AOSL20150002.

Kalnay, E., and Coauthors, 1996: The NCEP/NCAR 40-Year Reanalysis Project. Bull. Amer. Meteor. Soc., 77, 437-471, https://doi.org/ 10.1175/1520-0477(1996)077<0437:TNYRP>2.0.CO;2.

Kwon, M. H., J.-G. Jhun, B. Wang, S. I. An, and J. S. Kug, 2005: Decadal change in relationship between East Asian and WNP summer monsoons. Geophys. Res. Lett., 32, L16709, https:// doi.org/10.1029/2005GL023026.

Li, H. X., H. P. Chen, and H. J. Wang, 2016: Changes in clustered extreme precipitation events in South China and associated atmospheric circulations. Int. J. Climatol., 36, 3226-3236, https://doi.org/10.1002/joc.4549.

Li, X. Z., and W. Zhou, 2012: Quasi-4-yr coupling between El Niño-Southern Oscillation and water vapor transport over East Asia-WNP. J. Climate, 25, 5879-5891, https://doi.org/ 10.1175/JCLI-D-11-00433.1.

—, Z. P. Wen, W. Zhou, and D. X. Wang, 2012: Atmospheric water vapor transport associated with two decadal rainfall shifts over East China. J. Meteor. Sci., 90, 587-602, https:// doi.org/10.2151/jmsj.2012-501.

_ , W. Zhou, D. Chen, C. Li, and J. Song, 2014: Water vapor and moisture budget over eastern China: Remote forcing from the two types of El Niño. J. Climate, 27, 8778-8792, https://doi.org/ 10.1175/JCLI-D-14-00049.1.

Liu, Z. X., Y. Lian, Z. T. Gao, and B. Z. Shen, 2002: Analyses of the Northern Hemisphere circulation characters during northeast cold vortex persistence. Chin. J. Atmos. Sci., 26, 361-372.

Lu, R. Y., B. W. Dong, and H. Ding, 2006: Impact of the Atlantic Multidecadal Oscillation on the Asian summer monsoon. Geophys. Res. Lett., 33, L24701, https://doi.org/10.1029/ 2006 GL027655.
Ma, H. Y., Y. L. Zhu, and W. Hua, 2019: Interdecadal change in the South Asian summer monsoon rainfall in 2000 and contributions from regional tropical SST. Atmos. Ocean. Sci. Lett., 12, 399-408, https://doi.org/10.1080/16742834.2019.1648168.

Plumb, R. A., 1985: On the three-dimensional propagation of stationary waves. J. Atmos. Sci., 42, 217-229, https://doi.org/ 10.1175/1520-0469(1985)042<0217:OTTDPO > 2.0.CO;2.

Shen, B. Z., Z. D. Lin, R. Y. Lu, and Y. Lian, 2011: Circulation anomalies associated with interannual variation of early- and late-summer precipitation in Northeast China. Sci. China Earth Sci., 54, 1095-1104, https://doi.org/10.1007/s11430-0114173-6.

Sun, B., and H. J. Wang, 2014a: Inter-decadal transition of the leading mode of inter-annual variability of summer rainfall in East China and its associated atmospheric water vapor transport. Climate Dyn., 44, 2703-2722, https://doi.org/10.1007/ s00382-014-2251-0.

_ and _ 2014b: Moisture sources of semiarid grassland in China using the Lagrangian particle model FLEXPART. J. Climate, 27, 2457-2474, https://doi.org/10.1175/JCLI-D-1300517.1.

, and - 2015: Analysis of the major atmospheric moisture sources affecting three sub-regions of East China. Int. J. Climatol., 35, 2243-2257, https://doi.org/10.1002/joc.4145.

Sun, J. Q., and H. J. Wang, 2006: Regional difference of summer air temperature anomalies in Northeast China and its relationship to atmospheric general circulation and sea surface temperature. Chin. J. Geophys., 49, 588-598, https://doi.org/10.1002/ cjg2.872.

, and - 2012: Changes of the connection between the summer North Atlantic Oscillation and the East Asian summer rainfall. J. Geophys. Res., 117, D08110, https://doi.org/ 10.1029/2012JD017482.

Sun, L., B. Shen, Z. Gao, B. Sui, L. Bai, S.-H. Wang, G. An, and J. Li, 2007: The impacts of moisture transport of East Asian monsoon on summer precipitation in northeast China. Adv. Atmos. Sci., 24, 606-618, https://doi.org/10.1007/s00376-007-0606-8.

- _ - B. Sui, and B. Huang, 2017: The influences of East Asian monsoon on summer precipitation in Northeast China. Climate Dyn., 48, 1647-1659, https://doi.org/10.1007/s00382016-3165-9.

Wang, H. J., 2000: The interannual variability of East Asian monsoon and its relationship with SST in a coupled atmosphere-ocean-land climate model. Adv. Atmos. Sci., 17, 31-47, https://doi.org/10.1007/s00376-000-0041-6.

, 2002: The instability of the East Asian summer monsoonENSO relations. Adv. Atmos. Sci., 19, 1-11, https://doi.org/ 10.1007/s00376-002-0029-5.

, and H. P. He, 2015: The North China/Northeastern Asia severe summer drought in 2014. J. Climate, 28, 6667-6681, https://doi.org/10.1175/JCLI-D-15-0202.1.

Wang, L., W. Chen, and R. H. Huang, 2008: Interdecadal modulation of PDO on the impact of ENSO on the East Asian winter monsoon. Geophys. Res. Lett., 35, L20702, https:// doi.org/10.1029/2008GL035287.

Wang, Y., B. Zhou, D. Qin, J. Wu, R. Gao, and L. Song, 2017: Changes in mean and extreme temperature and precipitation over the arid region of northwestern China: Observation and projection. Adv. Atmos. Sci., 34, 289-305, https://doi.org/ 10.1007/s00376-016-6160-5.

Wu, J., and X. J. Gao, 2013: A gridded daily observation dataset over China region and comparison with the other datasets (in Chinese). Chin. J. Geophys., 56, 1102-1111. 
Wu, R. G., S. Yang, S. Liu, Y. Lian, and Z. T. Zong, 2011: Northeast China summer temperature and North Atlantic SST. J. Geophys. Res., 116, D16116, https://doi.org/10.1029/2011JD015779.

_- P. Zhao, and G. Liu, 2014: Change in the contribution of spring snow cover and remote oceans to summer air temperature anomaly over Northeast China around 1990. J. Geophys. Res. Atmos., 119, 663-676, https://doi.org/10.1002/ 2013JD020900.

Yao, X. P., and M. Dong, 2000: Research on the features of summer rainfall in Northeast China (in Chinese). Quart. J. Appl. Meteor., 11, 297-303..

Yim, S. Y., J. G. Jhun, and S. W. Yeh, 2008: Decadal change in the relationship between East Asian-western North Pacific summer monsoons and ENSO in the mid-1990s. Geophys. Res. Lett., 35, L20711, https://doi.org/10.1029/2008GL035751.

Yoo, S. H., S. Yang, H. J. Choi, and J. G. Jhun, 2004: Influences of tropical western and extratropical Pacific SST on East and Southeast Asian climate in the summers of 1993-94. J. Climate, 17, 2673-2687, https://doi.org/10.1175/1520-0442(2004)017<2673: IOTWAE $>2.0 . \mathrm{CO} ; 2$.

Zhang, R., and T. L. Delworth, 2007: Impact of the Atlantic Multidecadal Oscillation on North Pacific climate variability. Geophys. Res. Lett., 34, L23708, https://doi.org/10.1029/ 2007 GL031601.

Zhang, Y., J. M. Wallace, and N. Iwasaka, 1996: Is climate variability over the North Pacific a linear response to ENSO? J. Climate, 9 , 1468-1478, https://doi.org/10.1175/1520-0442(1996)009<1468: ICVOTN $>2.0 . \mathrm{CO} ; 2$.

Zhang, Z. Q., X. G. Sun, and X. Q. Yang, 2018: Understanding the interdecadal variability of East Asian summer monsoon pre- cipitation: Joint influence of three oceanic signals. J. Climate, 31, 5485-5506, https://doi.org/10.1175/JCLI-D-17-0657.1.

Zhou, B. T., and H. J. Wang, 2006: Relationship between the boreal spring Hadley circulation and the summer precipitation in the Yangtze River valley. J. Geophys. Res., 111, D16109, https:// doi.org/10.1029/2005JD007006.

— , Y. Xu, J. Wu, S. Dong, and Y. Shi, 2016: Changes in temperature and precipitation extreme indices over China: Analysis of a high-resolution grid dataset. Int. J. Climatol., 36, 1051-1066, https://doi.org/10.1002/joc. 4400 .

Zhou, L.-T., 2014: Interdecadal variability in large and small warm pools in western Pacific and their association with rainfall anomalies. Atmos. Oceanic Sci. Lett., 7, 56-61, https://doi.org/ 10.3878/j.issn.1674-2834.13.0066.

Zhou, M. Z., H. J. Wang, S. Yang, and K. Fan, 2013: Influence of springtime North Atlantic Oscillation on crops yields in Northeast China. Climate Dyn., 41, 3317-3324, https://doi.org/ 10.1007/s00382-012-1597-4.

Zhu, Y. L., 2011: A seasonal prediction model for the summer rainfall in Northeast China using the year-to-year increment approach. Atmos. Oceanic Sci. Lett., 4, 146-150, https:// doi.org/10.1080/16742834.2011.11446920.

—, H. J. Wang, W. Zhou, and J. H. Ma, 2011: Recent changes in the summer precipitation pattern in East China and the background circulation. Climate Dyn., 36, 1463-1473, https:// doi.org/10.1007/s00382-010-0852-9.

, _ - J. H. Ma, T. Wang, and J. Q. Sun, 2015: Contribution of the phase transition of Pacific Decadal Oscillation to the late 1990s' shift in East China summer rainfall. J. Geophys. Res. Atmos., 120, 8817-8827, https://doi.org/10.1002/2015JD023545. 